\title{
Quality of life improvement following parathyroid surgery: a two-year review from a single surgical centre
}

\section{N Caton, K Varadharajan, N Choudhury}

\section{Background:}

Parathyroidectomy offers definitive treatment for primary hyperparathyroidism, for symptomatic and asymptomatic patients, to prevent future complications of the disease.

\section{Objectives:}

Evaluate quality of life changes following parathyroidectomy.

\section{Methods:}

Retrospective study within a single centre using the Glasgow Benefit Inventory $(\mathrm{GBI})$ to assess quality of life changes following parathyroidectomy for primary hyperparathyroidism.

\section{Results:}

42 patients were assessed using the validated GBI. 23/42 patients were symptomatic and in 17/42, hypercalcaemia was an incidental finding, and the patients were asymptomatic. GBI analysis identified that 27 patients $(64 \%)$ expressed a benefit (rated as score $>0), 8(19 \%)$ had no benefit $($ score $=0)$ and $6(14 \%)$ experienced negative effects (score $<0)$ postoperatively. The mean GBI score was 21.0 (95\% confidence interval: 13.0 • to 29.0 ). Of the incidental, asymptomatic patients, $47 \%$ experienced an overall benefit.

6 patients experienced an overall negative effect; 3 were asymptomatic pre-operatively, one had a co-existing recurrent laryngeal nerve palsy from previous subtotal thyroidectomy for Graves' disease. There was no clear explanation as to the worse outcome in the other two patients.

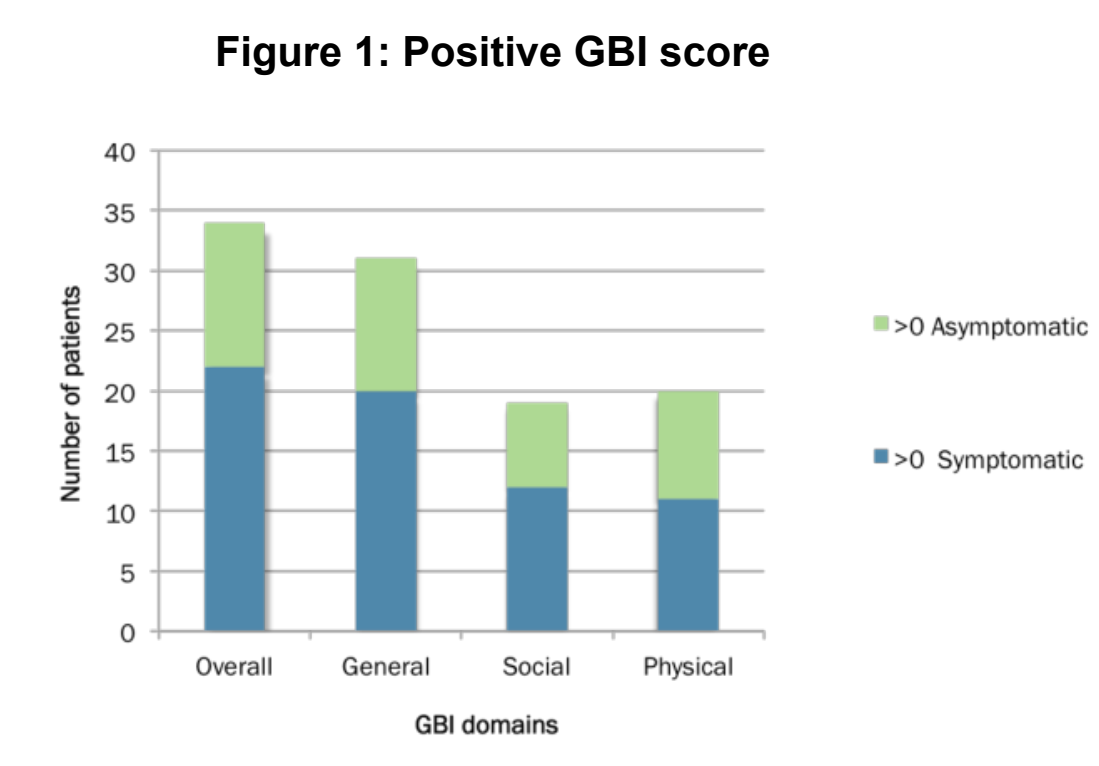

Figure 2: No change in GBI score

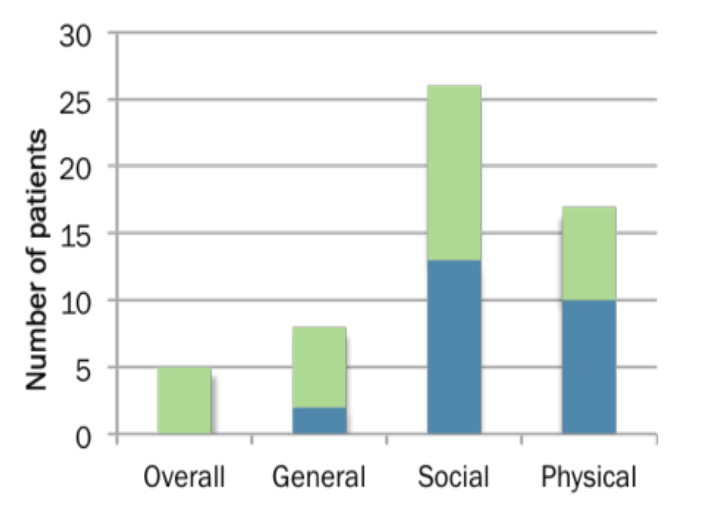

$=0$ Asymptomatic - 0 Symptomatic

Figure 3: Negative GBI score

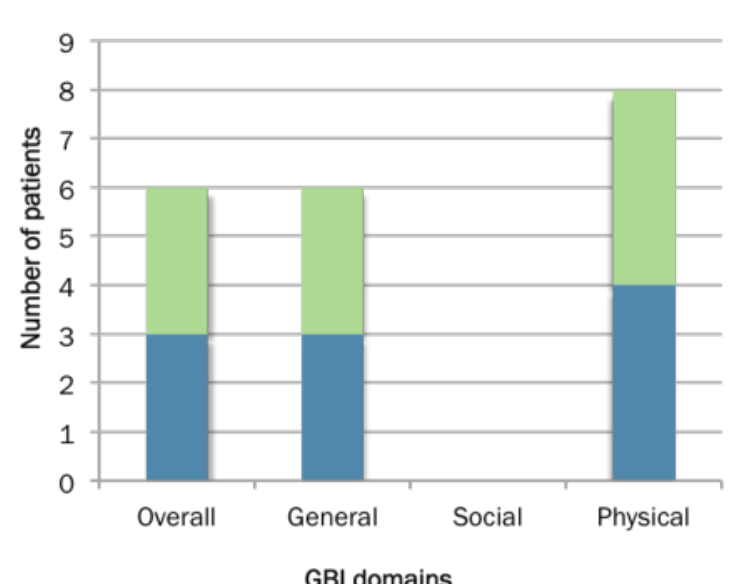

For the remaining pre-operatively symptomatic patients, there were identifiable reasons that may have contributed to their negative score, including, post operative hypocalcaemia, low vitamin $D$ levels, and an episode of panproctocolitis. We had no post-operative complications of recurrent laryngeal nerve palsy or haematoma.

\section{Conclusions:}

- Parathyroidectomy offers considerable positive patient-perceived benefit for both symptomatic and asymptomatic patients $(60 \%$ experienced an overall benefit).

- Patient-reported outcome measures are increasingly recognised as an important adjunctive tool in the assessment of surgical outcomes.

- Our GBI results (mean 19.1 \{95\% Cl: 12.8 to 25.4$\}$ ) are comparable with GBI scores for mastoid surgery (14.2), sialendoscopy (13.4), tonsillectomy ( 15.8 cold steel and 11.6 hot).

- Surgical aims are correction of hypercalcaemia and to improve patients' overall quality of life.

Parathyroidectomy is a safe operation in appropriately selected patients at high volume/specialist centres.

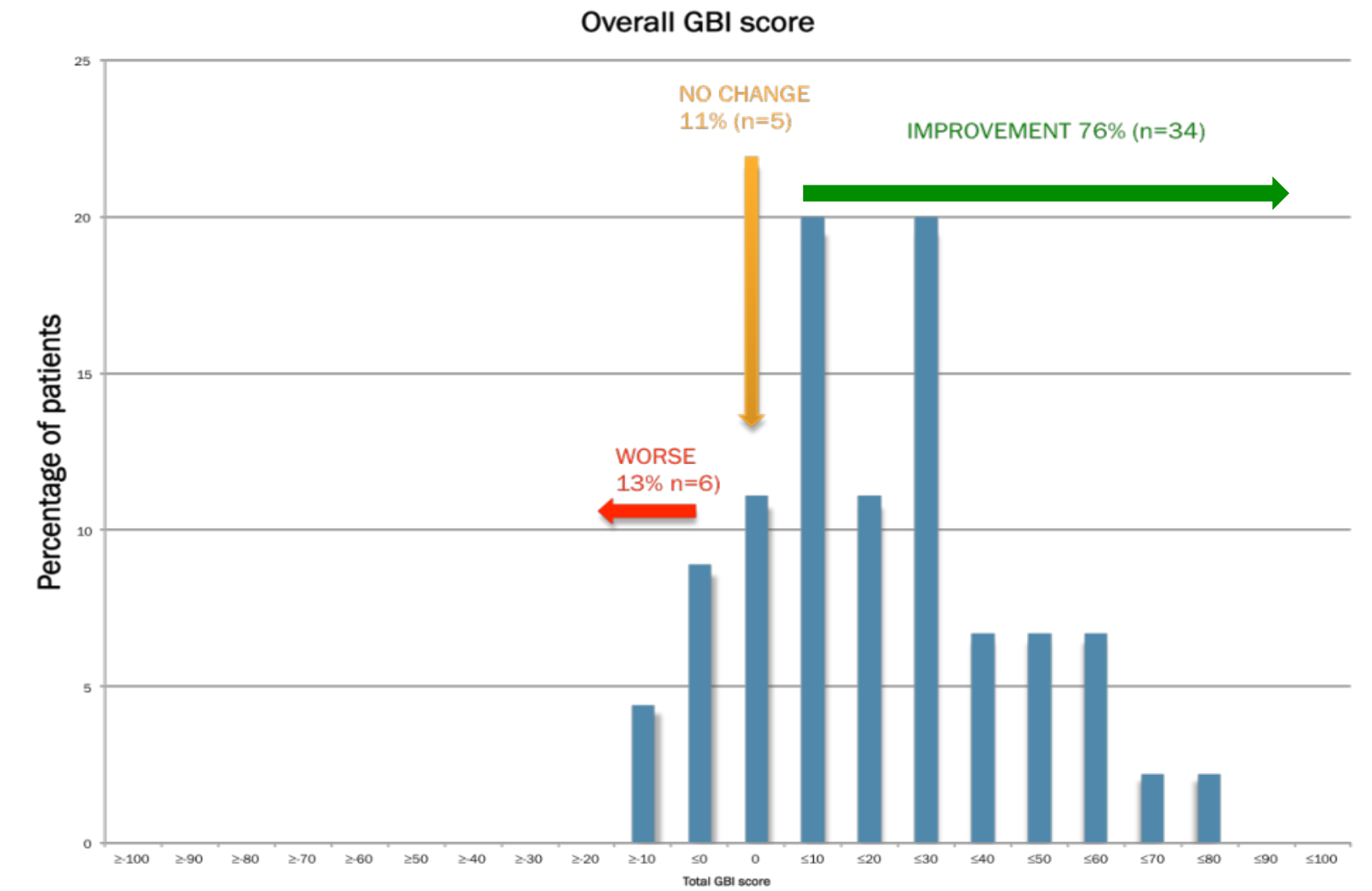

Table 1: Descriptive statistics for the GBI overall score and the 3 subdomains: General, Social and Physical.

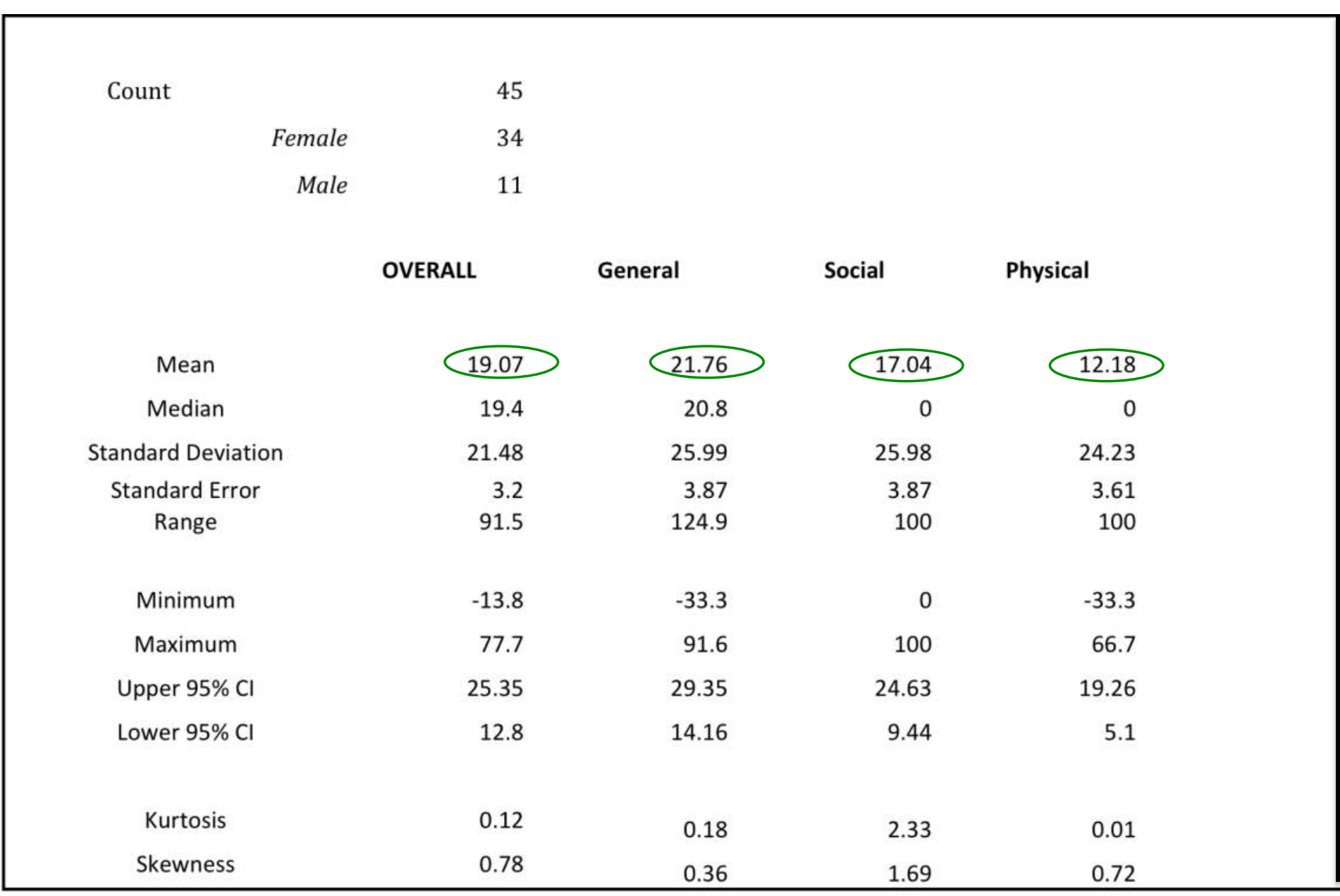

